\title{
openheart Association of coronary angiographic lesions and mortality in patients over 80 years with NSTEMI
}

\author{
Anwar J Siddiqui (D) , ${ }^{1,2}$ Elmir Omerovic (D) , ${ }^{3}$ Martin J Holzmann (D) , ${ }^{4}$ Felix Böhm ${ }^{1,5}$
}

To cite: Siddiqui AJ,

Omerovic E, Holzmann MJ, et al. Association of coronary angiographic lesions and mortality in patients over 80 years with NSTEMI. Open Heart 2022;9:e001811. doi:10.1136/ openhrt-2021-001811

MJH is deceased

Received 8 August 2021

Accepted 9 January 2022

Check for updates

(c) Author(s) (or their employer(s)) 2022. Re-use permitted under CC BY-NC. No commercial re-use. See rights and permissions. Published by BMJ.

${ }^{1}$ Department of Medicine, Karolinska Institutet, Stockholm, Sweden

${ }^{2}$ Department of Emergency and Reparative Medicine, Karolinska University Hospital, Stockholm, Sweden

${ }^{3}$ Department of Cardiology,

Sahlgrenska University Hospital, Gothenburg, Sweden

${ }^{4}$ Institution for Medicine,

Karolinska Institute, Stockholm,

Sweden

${ }^{5}$ Department of Cardiology, Karolinska Institutet, Stockholm, Sweden

Correspondence to Dr Anwar J Siddiqui; anwar. siddiqui@regionstockholm.se

\section{ABSTRACT}

Objective Coronary angiography (CA) and percutaneous coronary intervention ( $\mathrm{PCl}$ ) is of great importance during non-ST-segment elevation myocardial infarction (NSTEMI) management. Coronary artery lesions and their association to mortality in elderly patients with NSTEMI was investigated.

Methods Patients $>80$ years of age who underwent CA at index NSTEMI during 2011-2014 were included. Data were collected from the Swedish Coronary Angiography and Angioplasty Registry and Swedish Web-system for Enhancement and Development of Evidence-based care in Heart disease Evaluated According to Recommended Therapies registries. Coronary lesions were categorised into; one vessel disease (1VD), multi-vessel disease (MVD) and left main disease (LMD) and $0 \%-49 \%$ stenosis grade were considered as controls.

Cox regression was used to estimate HRs for all-cause mortality associated with coronary lesions. Survival benefit was determined after $\mathrm{PCl}$ and in relation to if revascularisation was complete or incomplete and any complications in the Cath lab was assessed.

Results Five thousand seven hundred and seventy patients with history of CA and PCl were included, 10\% had normal coronary arteries, 26\% had 1VD, 50\% MVD and $14 \%$ LMD. Mortality was higher in patients with $1 \mathrm{VD}$, MVD and LMD: HR 1.8 (1.3-2.5), HR 2.2 (1.6-3.0) and HR 2.8 (2.1-3.9), respectively. PCl were treated in $84 \%$ of $1 \mathrm{VD}, 73 \%$ MVD, and $54 \%$ in LMD. Survival was higher with PCI HR 0.85 (0.73-0.99). MVD had lower adjusted mortality HR $0.71(0.58-0.87)$ compared with patients with MVD who did not undergo PCl. Complications and mortality were higher in patients with $\mathrm{LMD}$ both during $\mathrm{CA}$ and $\mathrm{PCl}$, HR 2.9 (1.1-7.6) and HR 4.5 (1.6-12.5).

Conclusion Coronary lesions ( $>50 \%$ stenosis) are strong predictors of mortality in elderly patients with NSTEMI. MVD is common and PCl treatment is associated with increased survival.

\section{INTRODUCTION}

The ageing population is growing and their morbidity and mortality due to coronary heart disease is evidently increasing with increasing age. ${ }^{1}$ Clinical assessment of ischaemic burden due to non-ST-segment elevation myocardial infarction (NSTEMI) in elderly patients is challenging. Besides their

\section{Key questions}

What is already known about this subject?

- It has been reported that elderly patients frequently have left main disease (LMD) or multi-vessel disease (MVD) leading to poor outcome in non-STsegment elevation myocardial infarction (NSTEMI). Coronary angiography (CA) as well as percutaneous coronary intervention (PCl) is not offered frequently to elderly patients with NSTEMI.

What does this study add?

- Any coronary artery lesion (>50\% stenosis) in elderly during NSTEMI is a strong predictor for mortality. MVD was the predominant variant of vessel disease in our cohort and patients who underwent PCI had a survival benefit compared with patients undergoing conservative treatment. Elderly patients with LMD had no survival benefit of $\mathrm{PCl}$.

How might this impact on clinical practice?

- Our findings suggest that there are survival benefit of $\mathrm{CA}$ and subsequent $\mathrm{PCI}$ treatment in patients over 80 years old with NSTEMI.

known comorbidities like previous myocardial infarction (MI), diabetes, stroke, chronic kidney disease and chronic heart failure, many of these patients have advanced atherosclerotic disease, which leads to chronic angina. ${ }^{2}$ Interestingly, many of the elderly patients do not have classic chest pain as presenting symptom, but rather many other diffuse symptoms in the emergency department. ${ }^{34}$ Serial ECG and cardiac ischaemic markers such as troponins are important for initial diagnosis, but greater baseline variabilities of ECG and troponins are frequent problems in the elderly. As a result, symptom onset to diagnosis of acute coronary syndrome or NSTEMI is often delayed according to what is recommended by present guidelines. Moreover, non-cardiac emergencies like sepsis, pneumonia, chronic obstructive pulmonary disease exacerbation can sometimes mimic a clinical scenario like NSTEMI. In fact, these medical emergencies in elderly can provoke 
ischaemia in the heart resulting in type 2 MI. ${ }^{5}$ Despite the ability and improvement of non-invasive imaging modalities such as echocardiography, CT/MR-angiography to assess global heart function as well as to visualise and characterise the coronary arteries, invasive coronary angiography (CA) remains the 'gold standard'. Indeed, $\mathrm{CA}$ and subsequent possible $\mathrm{PCI}$ is of great significance in patient management during NSTEMI regardless of age. ${ }^{7}$ However, in clinical practice less than half of the elderly patients with NSTEMI are offered CA, and yet again many of them are not offered any PCI or coronary artery bypass graft $(\mathrm{CABG}) .^{8}$ In addition to unclear benefit of revascularisation in many elderlies, fear for procedural complications such as bleeding, stroke as well as contrast induced nephropathy are the main reasons for not referring for invasive angiography and PCI. ${ }^{78}$ However, it has recently been reported that PCI or angiogram related major vascular complications and bleeding is not as high in elderly as reported before. ${ }^{9}{ }^{10}$ Importantly, PCI is instead a treatment of choice in elderly that may lead to a survival benefit. ${ }^{11} 12$ Therefore, we sought to investigate and compare CA lesions and their association to

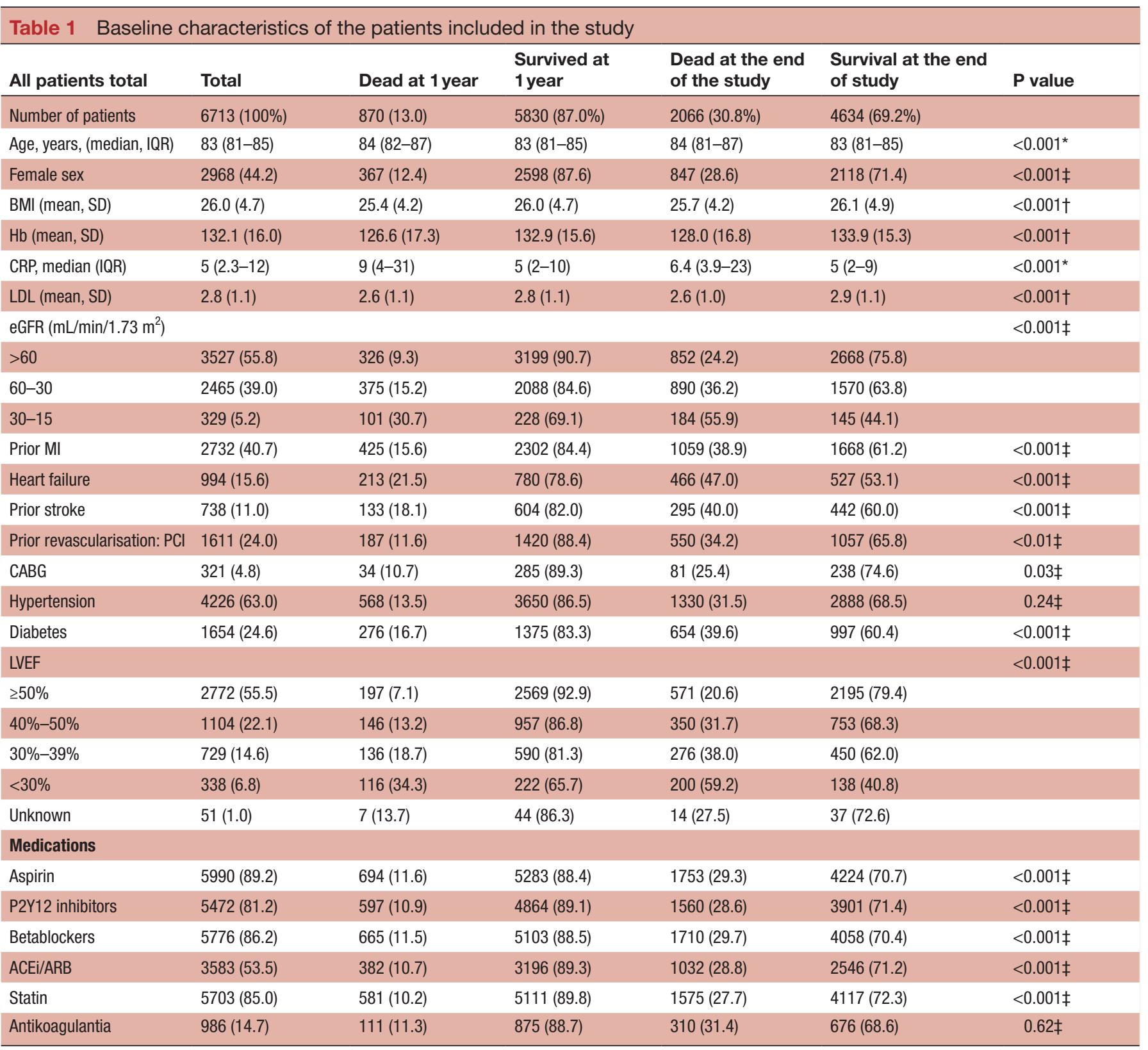

$P$ value indicate overall survival comparing between treatments.

Data are number of patients and percentages, unless otherwise noted.

*T-test.

†Mann-Whitney test.

$\mp \chi^{2}$ test.

ACEi, ACE inhibitor; ARB, angiotensin II receptor antagonists; BMI, body mass index; BMS, bare metal stent; CABG, coronary artery bypass graft; CRP, C reactive protein; DES, drug eluting stent; eGFR, estimated glomerular filtration rate; Hb, haemoglobin; LDL, low density lipoprotein; LVEF, left ventricular ejection fraction; MI, myocardial infarction; $\mathrm{PCl}$, percutaneous coronary intervention. 
Coronary artery disease

\begin{tabular}{|c|c|c|c|c|}
\hline All patients total & Total & $\mathrm{PCl}$ & Conservative & $P$ value \\
\hline Number of patients & $5770(100 \%)$ & $3868(67.0)$ & $1902(33.0)$ & \\
\hline Age, years, (median, IQR) & $83(81-85)$ & $83(81-85)$ & $83(81-85)$ & $<0.001^{*}$ \\
\hline Female & $2568(44.5)$ & $1655(64.5)$ & $913(35.5)$ & $<0.001 \ddagger$ \\
\hline Male & $3202(55.5)$ & $2213(69.1)$ & 989 (30.9) & \\
\hline BMI (mean, SD) & $26.0(4.7)$ & $26.0(5.1)$ & $25.8(4.0)$ & $0.266 \dagger$ \\
\hline $\mathrm{Hb}$ (mean, SD) & $132.1(16.0)$ & $133.5(15.3)$ & $132.1(16.0)$ & $<0.01 \dagger$ \\
\hline CRP, median (IQR) & $5(2.3-12)$ & $5(2-10.5)$ & $5(2.8-13)$ & $<0.01^{*}$ \\
\hline LDL (mean, SD) & $2.8(1.1)$ & $2.4(1.1)$ & $2.8(1.1)$ & $<0.001^{*}$ \\
\hline $\operatorname{eGFR}\left(\mathrm{mL} / \mathrm{min} / 1.73 \mathrm{~m}^{2}\right)$ & & & & $0.75 \ddagger$ \\
\hline$>60$ & $3123(54.1)$ & $2077(66.5)$ & $1046(33.5)$ & \\
\hline $60-30$ & $2071(35.8)$ & $1397(67.5)$ & $674(32.5)$ & \\
\hline $30-15$ & $260(4.5)$ & $172(66.2)$ & $88(33.9)$ & \\
\hline Prior Ml & $2046(35.5)$ & $1368(35.4)$ & $678(35.7)$ & $0.805 \ddagger$ \\
\hline Heart failure & $686(12.0)$ & $429(11.7)$ & $257(14.3)$ & $<0.01 \ddagger$ \\
\hline Prior stroke & $605(10.5)$ & $394(10.2)$ & $211(11.2)$ & $0.28 \ddagger$ \\
\hline Prior revascularisation: $\mathrm{PCl}$ & $1051(18.2)$ & 759 (19.6) & $292(15.4)$ & $<0.001 \ddagger$ \\
\hline CABG & $309(5.3)$ & $28(0.7)$ & $281(14.8)$ & $<0.001 \ddagger$ \\
\hline Hypertension & 3604 (62.5) & $2387(61.7)$ & $1217(64.0)$ & $0.19 \ddagger$ \\
\hline Diabetes & $1363(23.6)$ & $888(23.0)$ & $475(25.0)$ & $0.09 \ddagger$ \\
\hline LVEF & & & & $<0.126$ \\
\hline$\geq 50 \%$ & $2533(43.9)$ & 1717 (67.8) & $816(32.2)$ & \\
\hline $40 \%-50 \%$ & $976(17.0)$ & $668(68.4)$ & $308(31.6)$ & \\
\hline $30 \%-39 \%$ & $656(11.4)$ & 419 (63.9) & $237(36.1)$ & \\
\hline$<30 \%$ & $285(4.9)$ & $178(62.5)$ & 107 (37.5) & \\
\hline Unknown & $51(1.0)$ & $30(66.7)$ & $15(33.3)$ & \\
\hline \multicolumn{5}{|l|}{ Medications } \\
\hline Aspirin & $5224(90.5)$ & $3600(93.3)$ & $1624(85.5)$ & $<0.001 \ddagger$ \\
\hline P2Y12 inhibitors & $4772(82.7)$ & 3654 (94.7) & 1118 (58.8) & $<0.001 \ddagger$ \\
\hline Betablockers & $4964(86.0)$ & $3344(86.7)$ & $1620(85.3)$ & $0.14 \ddagger$ \\
\hline ACEi/ARB & $3160(54.8)$ & $2197(56.9)$ & $963(50.7)$ & $<0.001 \ddagger$ \\
\hline Statin & $4958(85.9)$ & $3426(88.6)$ & $1532(80.6)$ & $<0.001 \ddagger$ \\
\hline Antikoagulantia & $805(13.9)$ & $476(12.3)$ & $329(17.3)$ & $<0.001 \ddagger$ \\
\hline
\end{tabular}

Treatment data available for 5770 patients, median follow-up time: 2.6 years $(\mathrm{min}=0$, $\max =5.2$ ).

Data are number of patients and percentages, unless otherwise noted.

*Mann-Whitney test.

†T-test.

$\mp \chi^{2}$ test.

ACEi, ACE inhibitor; ARB, angiotensin Il receptor antagonists; BMI, body mass index; BMS, bare metal stent; CABG, coronary artery bypass graft;

CRP, C reactive protein; DES, drug eluting stent; eGFR, estimated glomerular filtration rate; Hb, haemoglobin; LDL, low density lipoprotein; LVEF, left

ventricular ejection fraction; $\mathrm{MI}$, myocardial infarction; $\mathrm{PCl}$, percutaneous coronary intervention.

outcomes in patients over 80 years of age with NSTEMI. In addition, we wanted to investigate the association between use of PCI and outcomes in this patient group.

\section{METHODS}

\section{Data sources and study population}

The study includes patients $>80$ years of age with NSTEMI who had undergone CA during 2011-2014 in Sweden. Data was collected from the Swedish Web-system for Enhancement and Development of Evidence-based care in Heart disease Evaluated According to Recommended Therapies (SWEDEHEART) and the Swedish Coronary Angiography and Angioplasty Registry (SCAAR) where records of all consecutive patients from all the centres $(\mathrm{n}=29)$ in Sweden who perform CA and PCI are documented. Initial $(n=6713)$ patient with NSTEMI where $(\mathrm{n}=5770)$ patients with a history of CA with or without subsequent PCI during index hospitalisation for NSTEMI were identified and included in the study. All types of coronary lesions were identified and categorised into; 


\begin{tabular}{|c|c|c|c|c|c|c|c|}
\hline \multirow{2}{*}{$\begin{array}{l}\text { Variabels } \\
\text { All patients }\end{array}$} & \multirow[b]{2}{*}{ Total n (\%) } & \multicolumn{2}{|c|}{ Treatment received ${ }^{\star}$} & \multicolumn{4}{|l|}{ Mortality } \\
\hline & & $\begin{array}{l}\text { Conservative } \\
\text { treatment }\end{array}$ & $\mathrm{PCl}$ & Dead at 1 year & $\begin{array}{l}\text { Survived at } \\
1 \text { year }\end{array}$ & $\begin{array}{l}\text { Dead at the end } \\
\text { of study }\end{array}$ & $\begin{array}{l}\text { Survived at } \\
\text { the end of } \\
\text { studyt }\end{array}$ \\
\hline $\begin{array}{l}\text { Number of patients } \\
(\%)\end{array}$ & $5770(100)$ & $1902(33.0)$ & $3868(67.0)$ & $870(13.0)$ & $5830(87.0)$ & $2066(30.8)$ & $4634(69.2)$ \\
\hline Normal & $498(8.6)$ & $498(100.0)$ & $0(0.0)$ & $49(8.4)$ & $533(91.6)$ & $123(21.2)$ & $459(78.9)$ \\
\hline 1VD & $1513(26.2)$ & $242(16.0)$ & $1271(84.0)$ & $161(9.4)$ & $1557(90.6)$ & $412(24.0)$ & $1306(76.0)$ \\
\hline MVD & $2938(50.9)$ & $780(26.6)$ & $2158(73.4)$ & 437 (12.8) & $2986(87.2)$ & $1112(32.5)$ & $2311(67.5)$ \\
\hline LMD & $821(14.2)$ & $382(46.5)$ & $439(53.5)$ & $223(22.8)$ & 754 (77.2) & $419(42.9)$ & $558(57.1)$ \\
\hline
\end{tabular}

*Treatment data available for 5770 patients.

†Median follow-up time: 2.6 years $(\min =0, \max =5.2)$.

LMD, left main disease; MVD, multi-vessel disease; PCI, percutaneous coronary intervention; 1VD, one vessel disease.

one vessel disease (1VD), multi-vessel disease (MVD) and left main disease (LMD).${ }^{13}$ Patients with no lesions or atheromathosis $(0 \%-49 \%)$ stenosis grade were considered as normal coronary artery in this cohort.

Cox regression was used to estimate HRs for the primary outcome mortality; (a) crude, (b) adjusted for age and (c) fully adjusted (PCI, sex, diabetes, hypertension, previous stroke, previous MI, chronic kidney diseases and medications at discharge due to NSTEMI) for each type of coronary artery lesions (1VD, MVD and LMD) compared with normal. Further, if there was any survival benefit with PCI or conservative treatment was assessed and compared in patients with different types of coronary lesions. Secondary outcome were acute complications in the Cath lab due to CA or PCI. Baseline characteristics were assessed at the day of admission for NSTEMI.

\section{Exposure and outcome}

Exposure was all types of coronary lesions identified by CA irrespective of if PCI treatment was performed or not during hospitalisation for the index NSTEMI. Patients with stenoses of $<50 \%$ in all vessel's categories were considered normal coronary arteries. The primary outcomes were all-cause mortality in relation to (a)

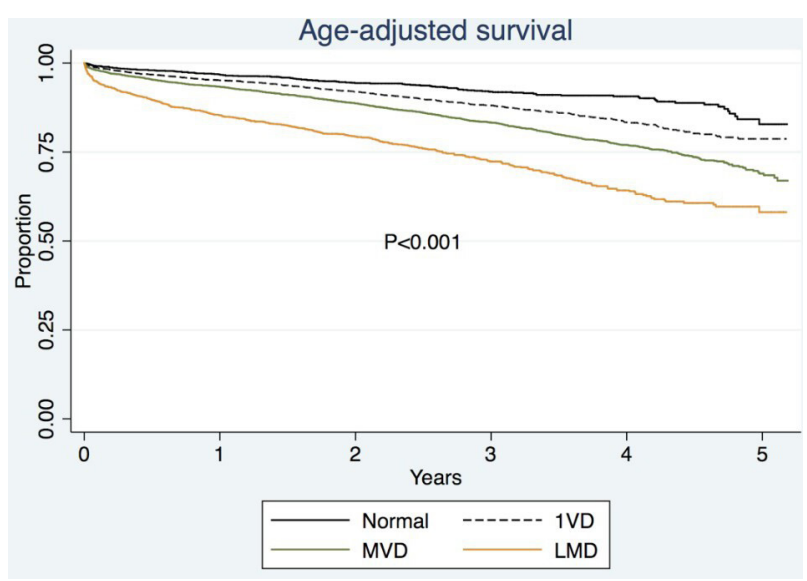

Figure 1 Overall age adjusted survival according to coronary angiography lesions. LMD, left main disease; MVD, multi-vessel disease; 1VD, one vessel disease. coronary lesions such as 1VD, MVD and LMD compared with controls lesion (b) all-cause mortality after PCI compared with those with conservative treatment. Further (c) if revascularisation by PCI was considered as complete or incomplete and the association to mortality was investigated. Complete revascularisation was considered when it meets the angiographic criteria that less than $10 \%$ of the left ventricle area is supplied by a stenosed (at least $60 \%$ stenosis) coronary artery. ${ }^{14}$ Secondary outcomes were complications due to CA or PCI. Complications data in the SCAAR registry is heterogeneous both from mild to severe forms of complications. Therefore, we have selected only severe form of complications (such as arrhythmia requiring acute interventions, haemodynamic complications, neurological complications, tamponade and death in the Cath lab) variables to estimate the impact of CA and PCI in the cohort.

\section{Follow-up}

Follow-up started at the time of acute CA or PCI during hospitalisation for the index NSTEMI and ended when the patient died, or at the end of follow-up which was on average a minimum of 2.6 years ( $\max 5.2$ years), whichever came first.

\section{Statistical methods}

Descriptive statistics were performed using means and SD for summarising numerical variables, and frequencies and percentages for categorical variables. Bivariate analyses with $\chi^{2}$ test were conducted to compare categorical variables with type of coronary lesions and mortality, while t-tests were used to compare numerical variables with type of treatment if any and mortality. Kaplan-Meier method was used to show cumulative survival in relation to coronary lesions and whether PCI was performed or not. Cox regression was used to estimate HR associated with different coronary lesions using patients with normal coronary arteries as reference. The proportionality of hazards was checked using Schoenfeld residuals, which confirmed the proportionality assumption. Further in separate model HR was also estimated with PCI compared with conservative treated lesions. HRs reported with $95 \%$ CIs and estimated (a) crude, (b) adjusted for age and (c) 
Table 4 Overall mortality according to angiography results, $\mathrm{HRs}(95 \% \mathrm{Cl})$

\begin{tabular}{llll}
\hline Variabels & & & \\
\hline All patients & $\begin{array}{l}\text { Crude HR } \\
\mathbf{( 9 5 \%} \mathbf{C l})\end{array}$ & Age adjusted $\mathbf{p}$ value & Fully adjusted $\mathbf{p}$ value \\
\hline Normal & Ref & Ref & Ref \\
\hline VD & $1.1(0.9$ to 1.4$)$ & $1.1(0.9-1.4)$ & $1.8(1.3-2.5)^{\star \star \star}$ \\
MVD & $1.7(1.4 \text { to } 2.0)^{\star \star \star}$ & $1.6(1.3-1.9)^{\star \star}$ & $2.2(1.6-3.0)^{\star \star \star}$ \\
LMD & $2.4(2.0 \text { to } 2.9)^{\star \star \star}$ & $2.2(1.8-2.7)^{\star \star \star}$ & $2.8(2.1-3.9)^{\star \star \star}$
\end{tabular}

${ }^{*} \mathrm{p}<0.05 ;{ }^{* *} \mathrm{p}<0.01 ;{ }^{* * *} \mathrm{p}<0.001$.

LMD, left main disease; MVD, multi-vessel disease; 1VD, one vessel disease.

adjusted for the potential confounders such as; sex, diabetes, hypertension, previous stroke, previous MI, chronic kidney diseases and medications at discharge due to NSTEMI. Logistic regression was used to calculate the odds of complications according to angiography results, overall and for the patients receiving PCI. $P$ values $<0.05$ were considered significant in the analysis. The collected data were analysed with STATA V.13.1 software (Stata Corporation).

The reporting of this observational cohort study followed the Strengthening the Reporting of Observational Studies in Epidemiology guidelines. ${ }^{15}$

\section{RESULTS}

\section{Baseline characteristics}

Five thousand seven hundred and seventy patients with CA data were included. Median age was 83 years and $44 \%$ were women. More than $55 \%$ of the patients had normal kidney function defined as an estimated glomerular filtration rate $(\mathrm{eGFR})>60 \mathrm{~mL} / \mathrm{min}$ using the CKDEPI equation to assess kidney function and a mean body mass index (BMI) of 26 . About $60 \%$ of the population had no history of MI while about one-fourth of the total population had a history of PCI. Very few patients had undergone CABG previously (table 1). Around $16 \%$ of the patients had a history of heart failure at admission while more than $55 \%$ of the total cohort had LVEF over $50 \%$ during hospitalisation for the index NSTEMI. Statin and beta blocker were the most frequent medications in the cohort besides antiplatelet agents.

\section{$\mathrm{CA}$ and $\mathrm{PCI}$}

A baseline characteristic of the patients with PCI or conservative treatment showed separately (table 2). About $10 \%$ of the patients had normal coronary arteries, 26\% had 1VD and 50\% had MVD (table 3). Around $14 \%$ had LMD in the cohort. Thirty-one per cent of the coronary lesions had $100 \%$ stenosis grade which indicates that many of these lesions might be considered as chronic total occlusion (CTO) of the coronary arteries. The overall survival at the end of the study (median follow-up 2.6 years) was $69 \%$ in the total cohort. Among patients with 1VD 1-year survival was $90 \%$ which was like patients with normal coronary arteries. Similar survival was also seen in patients with MVD while LMD had lower survival at 1 year after adjusting for age (figure 1). All patients with coronary disease lesions (defined as at least one lesion with $>50 \%$ stenosis): $1 \mathrm{VD}$, MVD and LMD had higher hazard of mortality compared with control (table 4). Regardless of the treatments (PCI or conservative management) for 1VD, MVD or LMD there were higher hazards of mortality HR 1.8 (1.3-2.5), HR 2.2 (1.6-3.0) and 2.8 (2.1-3.9), respectively compared with patients with normal vessels after adjusting for confounders (tables 5 and 6 ).

In total $67 \%$ of the total cohort underwent PCI during hospitalisation for the index NSTEMI. Patients with 1VD were most often treated with PCI $(84 \%)$ while $73 \%$ in MVD and 54\% in LMD underwent PCI. Thus, 1VD and MVD were more likely treated with PCI compared with LMD. In the group where PCI was considered as treatment

Table 5 Overall mortality according to angiography results among patients who received conventional treatment, HRs $(95 \% \mathrm{Cl})$

\begin{tabular}{|c|c|c|c|}
\hline \multicolumn{4}{|l|}{ Variables } \\
\hline All patients & $\begin{array}{l}\text { Crude HR } \\
(95 \% \mathrm{Cl})\end{array}$ & Age adjusted $p$ value & Fully adjusted $p$ value \\
\hline Normal & $0.5(0.4 \text { to } 0.7)^{\star \star *}$ & $0.6(0.4-0.8)^{* \star *}$ & $0.8(0.5-1.2)$ \\
\hline $1-V D$ & Ref & Ref & Ref \\
\hline MVD & $1.4(1.1 \text { to } 1.9)^{* \star}$ & $1.5(1.1-1.9)^{\star \star}$ & $1.9(1.3-2.8)^{\star \star \star}$ \\
\hline LMD & $1.5(1.1 \text { to } 2.0)^{\star \star}$ & $1.5(1.1-2.0)^{\star \star \star}$ & $2.0(1.4-3.0)^{\star \star}$ \\
\hline
\end{tabular}

${ }^{*} \mathrm{p}<0.05 ;{ }^{* *} \mathrm{p}<0.01 ;{ }^{* \star *} \mathrm{p}<0.001$.

LMD, left main disease; MVD, multi-vessel disease; 1VD, one vessel disease. 
Table 6 Survival analysis according to angio-results (overall mortality) among patients who received $\mathrm{PCl}, \mathrm{HRs}(95 \% \mathrm{Cl})$

\begin{tabular}{llll}
\hline Variabels & & & \\
\hline All patients & $\begin{array}{l}\text { Crude HR } \\
(\mathbf{9 5 \%} \mathbf{C l})\end{array}$ & Age adjusted $\mathbf{p}$ value & Fully adjusted $\mathbf{p}$ value \\
\hline Normal & - & - & - \\
IVD & Ref & Ref & Ref \\
MVD & $1.4(1.2 \text { to } 1.6)^{\star \star *}$ & $1.3(1.1-1.5)^{\star \star}$ & $1.0(0.9-1.2)$ \\
LMD & $2.2(1.8 \text { to } 2.6)^{\star \star *}$ & $1.9(1.6-2.3)^{\star \star *}$ & $1.6(1.2-2.0)^{\star \star *}$ \\
\hline
\end{tabular}

${ }^{*} \mathrm{p}<0.05 ;{ }^{* *} \mathrm{p}<0.01 ;{ }^{* \star *} \mathrm{p}<0.001$.

LMD, left main disease; MVD, multi-vessel disease; 1VD, one vessel disease.

of choice it resulted in a lower adjusted mortality HR $0.85(0.73-0.99, \mathrm{p}<0.04)$ compared with patients treated conservatively. However, when we investigated the individual coronary lesions type; the survival benefit of PCI disappeared in fully adjusted model in LMD (HR 0.97, $0.70-1.35$ ), higher mortality in patients with 1VD (HR 1.66, 1.1-2.4) while in MVD patients had 30\% lower mortality compared with patients treated conservatively (table 7).

\section{Complete versus incomplete revascularisation}

Of all 5770 patients undergoing CA, PCI was performed in $67 \%(\mathrm{n}=3868)$. In the patients where PCI was performed the operator indicated whether the revascularisation was considered complete or not. Our data suggest that patients with LMD were less likely to be considered as completely revascularised (28\%). While patients with IVD and MVD had higher possibilities of complete revascularisation (88\% and $32 \%$, respectively) ( $<<0.001,1 \mathrm{VD}$ vs LMD when fully adjusted).

\section{Complications}

CA with or without subsequent PCI was well tolerated in these elderly patients. Around $1.1 \%$ patients had different types of complications due to CA or PCI entered in the registry. There was no significant difference of complications in 1VD and MVD (table 8). While higher odds of complications during CA and PCI was observed in LMD; OR 2.9 (1.1-7.6) and OR 4.5 (1.6-12.5), respectively compared with 1VD (table 9).

\section{DISCUSSION}

This study demonstrates that CA during NSTEMI reveals predominantly multi-vessel coronary artery disease in patients over 80 years. About $14 \%$ of the patients had left main disease. Our data suggest that any coronary artery lesions ( $>50 \%$ stenosis) in elderly during NSTEMI is a strong prognostic factor for mortality. In fact, there are higher hazards of deaths among all categories of patients with coronary artery disease (1VD, MVD and LMD) compared with patients with normal vessels. Treatment with PCI for patients with MVD was associated with $29 \%$ survival benefit compared with patients who were treated conservatively. Severe complications were rare in this cohort. Higher rates of complications were seen in patients with LMD undergoing CA and PCI. Complete revascularisation is more likely achieved in elderly with 1VD but do not have any survival benefit compared with conservative treatment. Our results suggest that CA as well as PCI is well tolerated in the elderly patients with NSTEMI. PCI treatment increased survival compared with conservative treatment and our findings suggest that $\mathrm{CA}$ and PCI may be considered instead of conservative treatment also in the elderly.

Interestingly $10 \%$ of the studied population had normal coronary arteries which may be explained by either MI with non-obstructive coronary artery disease a condition which is present during takotsubo syndrome or type 2 MI. ${ }^{16}{ }^{17}$ Distinguishing between NSTEMI due to type $1 \mathrm{MI}$ and type 2 MI can be challenging in many elderly patients due to advanced underlying atherosclerotic lesions. ${ }^{18}$

Table $7 \mathrm{HRs}(95 \% \mathrm{Cl})$ for the risk of all-cause mortality associated with $\mathrm{PCl}$ versus no $\mathrm{PCl}$ stratified for coronary artery lesions in patients $>80$ years of age with non-ST elevation myocardial infarction

\begin{tabular}{|c|c|c|c|c|c|c|}
\hline & \multicolumn{2}{|c|}{$\begin{array}{l}\text { 1VD } \\
\text { (deaths }(n)=412(24 \%))\end{array}$} & \multicolumn{2}{|c|}{$\begin{array}{l}\text { MVD } \\
\text { (deaths }(n)=1112(32.5 \%))\end{array}$} & \multicolumn{2}{|c|}{$\begin{array}{l}\text { LMD } \\
\text { (deaths }(n)=419(42.9 \%))\end{array}$} \\
\hline & No PCl & $\mathrm{PCl}$ & No PCI & $\mathrm{PCl}$ & No $\mathrm{PCl}$ & $\mathrm{PCl}$ \\
\hline HR, adjusted for age & Ref. & 0.67 (0.51 to 0.87 ) & Ref. & 0.58 (0.51 to 0.67$)$ & Ref. & 0.86 (0.69 to 1.08$)$ \\
\hline HR, adjusted for confounders* & Ref. & 1.66 (1.11 to 2.49$)$ & Ref. & 0.71 (0.59 to 0.87$)$ & Ref. & 0.97 (0.70 to 1.35$)$ \\
\hline
\end{tabular}

${ }^{*}$ Full model was adjusted for all variables in table 1.

eGFR, estimated glomerular filtration rate; LMD, left main disease; MVD, multi-vessel disease; PCI, percutaneous coronary intervention; 1VD, one vessel disease. 
Table 8 Complications according to angiography results, OR $(95 \% \mathrm{Cl})$

\begin{tabular}{|c|c|c|c|c|c|}
\hline \multirow{2}{*}{$\begin{array}{l}\text { Variables } \\
\text { All patients }\end{array}$} & \multicolumn{2}{|c|}{ Complications } & \multicolumn{3}{|c|}{ Logistic regression } \\
\hline & No & Yes & $\begin{array}{l}\text { Crude OR } \\
(95 \% \mathrm{Cl})\end{array}$ & $\begin{array}{l}\text { Age-adjusted OR } \\
(95 \% \mathrm{Cl})\end{array}$ & $\begin{array}{l}\text { Fully adjusted OR } \\
(95 \% \mathrm{Cl})\end{array}$ \\
\hline Number of patients (\%) & $5693(98.7)$ & $77(1.3)$ & - & - & - \\
\hline Normal & $496(99.6)$ & $2(0.4)$ & 0.4 (0.1 to 1.8$)$ & $0.4(0.1$ to 1.9$)$ & 0.7 (0.1 to 6.9$)$ \\
\hline 1VD & $1499(99.1)$ & $14(0.9)$ & Ref. & Ref. & Ref. \\
\hline MVD & $2897(98.6)$ & $41(1.4)$ & 1.5 (0.8 to 2.7$)$ & 1.4 (0.8 to 2.6$)$ & $2.0(0.9$ to 4.4$)$ \\
\hline LMD & $801(97.6)$ & $20(2.4)$ & $2.5(1.3 \text { to } 5.1)^{\star \star}$ & $2.3(1.2 \text { to } 4.7)^{\star}$ & $2.9(1.1 \text { to } 7.6)^{*}$ \\
\hline
\end{tabular}

${ }^{*} \mathrm{p}<0.05 ;{ }^{* *} \mathrm{p}<0.01 ;{ }^{* * *} \mathrm{p}<0.001$.

LMD, left main disease; MVD, multi-vessel disease; 1VD, one vessel disease.

However, it has been suggested that even though CA reveal non-obstructive coronary arteries there is underlying ischaemia which might be the reason for NSTEMI. In fact, in a previous study it was found that up to $70 \%$ of the patients did not have any coronary lesions despite clinical evidence of myocardial ischaemia. ${ }^{19}$ Randomised studies are ongoing to find out an optimal treatment strategy in this category of myocardial ischaemia. Furthermore, it is noted that $33 \%$ of the patients who had a significant stenosis were not treated with PCI. This may due to that operators did not choose to perform PCI for complex lesion including CTO's of the coronary artery in this elderly cohort. ${ }^{2021}$

Previous studies emphasised on early invasive strategies using $\mathrm{CA}$ and $\mathrm{PCI}$ in patients over 75 years of age to reduce both mortality and re-infarction. ${ }^{22}$ In patients above the age of 80 years with NSTEMI a yearly mortality rate over $25 \%$ has been reported. ${ }^{23}$ It has been suggested that elderly patients often have concomitant LMD and heart failure; a combination which is often associated with poor prognosis during NSTEMI. ${ }^{24}$ While our data suggest that LMD is not the predominant types of coronary artery disease rather these patients often have MVD, while only $15 \%$ of the patients had heart failure at admission due to NSTEMI. Still, both complications and death were more common in patients who underwent $\mathrm{CA}$ and PCI who had LMD. In this cohort we could not detect any survival benefit with PCI among patients with LMD compared with conservatively treated patients, which may be due to insufficient numbers to draw any firm conclusion.
Most likely these patients are also disqualified from CABG due to advance age and existing comorbidities. However, heart failure defined according to LVEF $<50 \%$ was present in $40 \%$ of the cohort at index NSTEMI. Thus, higher mortality in patients with NSTEMI with reduced LVEF and concomitant coronary lesions is evident in elderly where a careful strategy should be taken based on individual clinical status as well as frailty. ${ }^{25}$

Patients with MVD are often elderly and it has been unclear whether these patients can get any benefit of complete revascularisation during acute coronary syndrome. In STEMI with MVD it has been suggested that complete revascularisation which includes PCI of nonculprit lesions is associated with reduced cardiovascular mortality compared with PCI of the culprit lesions only. ${ }^{26}$ However, the circumstances are different in NSTEMI with MVD where it is not always easy to identify the culprit lesion ${ }^{27}$ which may lead to treating the wrong vessel or even no vessel. However, a recent meta-analysis data suggests that elderly patients with NSTEMI with MVD can get survival benefit at the cost of increased bleeding with complete revascularisation compared with culprit only lesion. ${ }^{28}$ Even though it was rare with complete revascularisation in MVD patients in our cohort, we still found that PCI was associated with a survival benefit compared with conservative treatment. We observed that complete revascularisation was achieved to a great extent in $1 \mathrm{VD}$ patients undergoing PCI but was not associated with a survival benefit compared with conservative treatment. Previously reported data from COURAGE and TIME

\begin{tabular}{|c|c|c|c|}
\hline \multirow{2}{*}{$\begin{array}{l}\text { Variables } \\
\text { All patients }\end{array}$} & \multicolumn{3}{|c|}{ Logistic regression } \\
\hline & $\begin{array}{l}\text { Crude OR } \\
(95 \% \mathrm{Cl})\end{array}$ & $\begin{array}{l}\text { Age-adjusted OR } \\
(95 \% \mathrm{Cl})\end{array}$ & $\begin{array}{l}\text { Fully adjusted OR } \\
(95 \% \mathrm{Cl})\end{array}$ \\
\hline Normal & - & - & - \\
\hline 1VD & Ref. & Ref. & Ref. \\
\hline MVD & 1.6 (0.8 to 3.1$)$ & 1.5 (0.7 to 3.0$)$ & 2.0 (0.8 to 4.8$)$ \\
\hline LMD & $4.6(2.1 \text { to } 9.9)^{\star \star \star \cdot}$ & 4.1 (1.9 to 8.9$)^{* \star \star}$ & $4.5(1.6 \text { to } 12.5)^{\star \star}$ \\
\hline
\end{tabular}

${ }^{*} \mathrm{p}<0.05 ;{ }^{* *} \mathrm{p}<0.01 ;{ }^{* \star *} \mathrm{p}<0.001$.

LMD, left main disease; MVD, multi-vessel disease; $1 \mathrm{VD}$, one vessel disease. 
(Trial of Invasive vs Medical Therapy in the Elderly) suggest no clear long-term benefit by revascularisation in patients over 65 and 75 years of age compared with younger patients. ${ }^{29}{ }^{30}$ However, the number of elderly patients in these studies were small and the data are quite old and should be interpreted with caution in the context of recent developments of newer antithrombotic drugs and stents. In contrast, a randomised trial suggested survival free from a combined endpoint such as death, stroke, MI and need for revascularisation in patients over 80 years of age by an early invasive strategy which is in line with our observations. ${ }^{31}$

\section{Limitations and strengths of the study}

This is an observational cohort study so cautious interpretations of data in the context of any clinical setting should be considered, mainly because of the inherent risk with residual confounding that we could not control for. Due to the large samples sizes, the statistical tests detect small differences. The $\mathrm{p}$ values should be used with caution. Further, our main limitation of the study, along with every observational study that compares two treatment strategies, is confounding by indication. Even though we were able to control for the most important predictors of mortality, it is likely there were still patient characteristics that we had no information about which may have been the reason to withhold CA and subsequent PCI treatment or vice versa. However, the key strength of our study was the large cohort of patients over 80 years of age and the long follow-up, which led to many events, and a high precision in our estimates. A strength of the study is that $100 \%$ of all procedures in Sweden are registered in SCAAR, the Swedish nationwide angiogram and PCI registry which has been incorporated and merged with the SWEDEHEART registry. This means that we can get real-world data with great generalisability from this registry. In conclusion, our data indicate that elderly patients with NSTEMI often has multi-vessel coronary disease which is associated with higher mortality. However, we observed survival benefit with PCI in patients with MVD with minimal complications compared with conservative treatment.

\section{CONCLUSION}

Coronary lesions ( $>50 \%$ stenosis) are strong predictors of mortality in elderly patients with NSTEMI. MVD is common and PCI treatment is associated with increased survival. Prevalence of coronary heart disease may reach a plateau phase with increasing age but both morbidity and mortality in ageing patients due to cardiovascular disease is still a challenge. CA is not only a recommended investigation in patients with NSTEMI, but it can also give an assessment of patients at risk of death and future cardiovascular events as well as give an idea if revascularisation is possible either by PCI or CABG. Furthermore, it may give information whether revascularisation can alleviate angina symptom and thus improve their quality of life. Thus, our data are in accordance to ESC/ACC/AHA guidelines suggest that CA and PCI should be a rational approach during NSTEMI considering weight of potential risks and benefits in patients with advanced age.

Acknowledgements Our sincere gratitude to $\mathrm{Dr}$ Gaetano Marrone, $\mathrm{PhD}$, at the Department of Public Health Sciences, Karolinska Institutet, Stockholm, Sweden for data management and analysis support.

Contributors Study concept and design: AJS. Acquisition of data: AJS. Analysis and interpretation of data: all authors. Drafting of the manuscript: AJS, FB, EO and MJH. Critical revision of the manuscript for important intellectual content: EO, FB, MJH and AJS. Guarantor of the study: AJS.

Funding MJH holds research positions funded by the Swedish Heart-Lung Foundation (grant: 20170804) and the Stockholm County Council (grant: 20170686).

Competing interests None declared.

Patient consent for publication Not applicable.

Ethics approval There were no direct patient or public involvement in the study thus patients were waived from informed consent. The study was approved by the local ethics committee and adhered with the Declaration of Helsinki.

Provenance and peer review Not commissioned; externally peer reviewed.

Data availability statement Data are available upon reasonable request. Data may be obtained from a third party and are not publicly available. Open access to data is not allowed according to the Swedish law. According to the Swedish Ethics Review Act, the General Data Protection Regulation, and the Public Access to Information and Secrecy Act, patient data can only be made available, after legal review, to researchers who meet the criteria for access to this type of confidential data. However, given a reasonable request, additional analyses may be conducted after contacting the corresponding author.

Open access This is an open access article distributed in accordance with the Creative Commons Attribution Non Commercial (CC BY-NC 4.0) license, which permits others to distribute, remix, adapt, build upon this work non-commercially, and license their derivative works on different terms, provided the original work is properly cited, appropriate credit is given, any changes made indicated, and the use is non-commercial. See: http://creativecommons.org/licenses/by-nc/4.0/.

\section{ORCID iDs}

Anwar J Siddiqui http://orcid.org/0000-0001-8673-9380

Elmir Omerovic http://orcid.org/0000-0002-3875-8621

Martin J Holzmann http://orcid.org/0000-0001-8992-8347

\section{REFERENCES}

1 Townsend N, Nichols M, Scarborough P, et al. Cardiovascular disease in Europe--epidemiological update 2015. Eur Heart J 2015;36:2696-705.

2 Writing Group Members, Mozaffarian D, Benjamin EJ, et al. Heart disease and stroke statistics-2016 update: a report from the American heart association. Circulation 2016;133:e38-60.

3 Culić V, Eterović D, Mirić D, et al. Symptom presentation of acute myocardial infarction: influence of sex, age, and risk factors. Am Heart J 2002;144:1012-7.

4 Canto JG, Fincher C, Kiefe Cl, et al. Atypical presentations among Medicare beneficiaries with unstable angina pectoris. Am J Cardiol 2002;90:248-53.

5 Niccoli G, Scalone G, Crea F. Acute myocardial infarction with no obstructive coronary atherosclerosis: mechanisms and management. Eur Heart J 2015;36:475-81.

6 DeFilippis AP, Chapman AR, Mills NL, Nicholas L., et al. Assessment and treatment of patients with type 2 myocardial infarction and acute nonischemic myocardial injury. Circulation 2019;140:1661-78.

7 Alexander KP, Newby LK, Cannon CP, et al. Acute coronary care in the elderly, part I: Non-ST-segment-elevation acute coronary syndromes: a scientific statement for healthcare professionals from the American heart association Council on clinical cardiology: in collaboration with the Society of geriatric cardiology. Circulation 2007;115:2549-69.

8 Reinius P, Mellbin L, Holzmann MJ. Percutaneous coronary intervention versus conservative treatment for non ST-segment elevation myocardial infarction in patients above 80 years of age. Int J Cardiol 2018;15:57-61.

9 Fox KAA, Clayton TC, Damman P, Clayton TC, et al. Longterm outcome of a routine versus selective invasive strategy in 
patients with non-ST-segment elevation acute coronary syndrome a meta-analysis of individual patient data. J Am Coll Cardiol 2010;55:2435-45

10 Hamm CW, Bassand J-P, Agewall S, et al. ESC guidelines for the management of acute coronary syndromes in patients presenting without persistent ST-segment elevation: the task force for the management of acute coronary syndromes (ACS) in patients presenting without persistent ST-segment elevation of the European Society of cardiology (ESC). Eur Heart $J$ 2011;32:2999-3054.

11 Amsterdam EA, Wenger NK, Brindis RG. 2014 AHA/ACC guideline for the management of patients with non-ST-elevation acute coronary syndromes: a report of the American College of Cardiology/ American heart association Task force on practice guidelines. Circulation 2014:344-426.

12 Chhatriwalla AK, Amin AP, Kennedy KF, et al. Association between bleeding events and in-hospital mortality after percutaneous coronary intervention. JAMA 2013;309:1022-9.

13 Rao SV, Eikelboom JA, Granger CB, et al. Bleeding and blood transfusion issues in patients with non-ST-segment elevation acute coronary syndromes. Eur Heart J 2007;28:1193-204.

14 Cowley MJ, Vandermael M, Topol EJ, et al. Is traditionally defined complete revascularization needed for patients with multivessel disease treated by elective coronary angioplasty? multivessel angioplasty prognosis study (maps) group. J Am Coll Cardiol 1993;22:1289-97.

15 von Elm E, Altman DG, Egger M, et al. The strengthening the reporting of observational studies in epidemiology (STROBE) statement: guidelines for reporting observational studies. J Clin Epidemiol 2008;61:344-9.

16 Schneider B, Sechtem U. Influence of age and gender in takotsubo syndrome. Heart Fail Clin 2016;12:521-30.

17 Pasupathy S, Air T, Dreyer RP, et al. Systematic review of patients presenting with suspected myocardial infarction and nonobstructive coronary arteries. Circulation 2015;131:861-70.

18 Avezum A, Makdisse M, Spencer F, et al. Impact of age on management and outcome of acute coronary syndrome: observations from the global registry of acute coronary events (grace). Am Heart J 2005;149:67-73.

19 Bainey KR, Engstrøm T, Smits PC, et al. Complete vs CulpritLesion-Only revascularization for ST-segment elevation myocardia infarction: a systematic review and meta-analysis. JAMA Cardiol 2020;5:881-888.
20 Galassi AR, Tomasello SD, Reifart N, et al. In-Hospital outcomes of percutaneous coronary intervention in patients with chronic total occlusion: insights from the ERCTO (European registry of chronic total occlusion) registry. Eurolntervention 2011;7:472-9.

21 Grantham JA, Marso SP, Spertus J, et al. Chronic total occlusion angioplasty in the United States. JACC Cardiovasc Interv 2009;2:479-86.

22 Gale CP, Cattle BA, Woolston A, et al. Resolving inequalities in care? reduced mortality in the elderly after acute coronary syndromes. The myocardial ischaemia national audit project 2003-2010. Eur Heart $J$ 2012;33:630-9

23 Gaffar R, Habib B, Filion KB, et al. Optimal timing of complete revascularization in acute coronary syndrome: a systematic review and meta-analysis. J Am Heart Assoc 2017;6. doi:10.1161/ JAHA.116.005381. [Epub ahead of print: 10 Apr 2017].

24 Avezum A, Makdisse M, Spencer F, et al. Impact of age on management and outcome of acute coronary syndrome: observations from the global registry of acute coronary events (grace). Am Heart J 2005;149:67-73.

25 Murali-Krishnan R, Iqbal J, Rowe R, et al. Impact of frailty on outcomes after percutaneous coronary intervention: a prospective cohort study. Open Heart2015;2:e000294.

26 Mehta SR, Wood DA, Storey RF, et al. Complete revascularization with multivessel $\mathrm{PCl}$ for myocardial infarction. $\mathrm{N}$ Engl J Med Overseas Ed 2019;381:1411-21.

27 Heitner JF, Senthilkumar A, Harrison JK, et al. Identifying the Infarct-Related artery in patients with Non-ST-Segment-Elevation myocardial infarction. Circ Cardiovasc Interv 2019;12:e007305.

28 Gnanenthiran SR, Kritharides L, D'Souza M, D'Souza M, et al. Revascularisation compared with initial medical therapy for non-STelevation acute coronary syndromes in the elderly: a meta-analysis. Heart 2017;103:1962-9.

29 Mancini GBJ, Hartigan PM, Shaw LJ, et al. Predicting outcome in the courage trial (clinical outcomes utilizing revascularization and aggressive drug evaluation): coronary anatomy versus ischemia. JACC Cardiovasc Interv 2014;7:195-201.

30 Pfisterer M, Bertel O, Erne $\mathrm{P}$, et al. Trial of invasive versus medica therapy in elderly patients with chronic symptomatic coronary-artery disease (time): a randomised trial. Lancet 2001;358:951-7.

31 Tegn N, Abdelnoor M, Aaberge L, et al. Invasive versus conservative strategy in patients aged 80 years or older with non-ST-elevation myocardial infarction or unstable angina pectoris (after eighty study): an open-label randomised controlled trial. Lancet 2016;387:1057-65. 